\title{
The Microenvironment of Freeze-Injured Mouse Urinary Bladders Enables Successful Tissue Engineering
}

\author{
Tetsuya Imamura, Ph.D., ${ }^{1}$ Tokunori Yamamoto, M.D., Ph.D., ${ }^{2}$ Osamu Ishizuka, M.D., Ph.D., \\ Momokazu Gotoh, M.D., Ph.D., ${ }^{2}$ and Osamu Nishizawa, M.D., Ph.D.
}

\begin{abstract}
Mouse bone marrow-derived cells implanted into freeze-injured bladder walls form smooth muscle layers, but not in intact walls. We determined if the microenvironment within injured urinary bladders was supportive of smooth muscle layer development. The urinary bladders of female nude mice were freeze-injured for $30 \mathrm{~s}$. Three days later, the rate of blood flow in the wounded areas and in comparable areas of intact control urinary bladders was observed by charge-coupled device (CCD) video microscopy. Injured and control bladder walls were also analyzed histologically and cytologically. Growth factor mRNA expression was determined by real-time reverse transcription polymerase chain reaction arrays. The injured regions maintained a partial microcirculation in which blood flow velocity was significantly less than in controls. The injured bladder walls had few typical smooth muscle layers, and blood vessels in the walls had reduced smooth muscle content. The loss of smooth muscle cells in the bladder walls may have resulted in the formation of large porous spaces seen by scanning electron microscopy of the injured areas. The expression of nineteen growth-related mRNAs, including secreted phosphoprotein 1, inhibin $\beta-A$, glial cell line-derived neurotrophic factor, and transforming growth factor $\beta 1$, were significantly upregulated in the injured urinary bladders. In conclusion, the microenvironment in freeze-injured urinary bladders enables successful tissue engineering.
\end{abstract}

\section{Introduction}

$\mathbf{R}$ EGENERATIVE MEDICINE OFFERS great hope for the recovery of lost tissue and organ functions. ${ }^{1,2}$ Bone marrow-derived cells with the potential for proliferation and differentiation have been vigorously investigated for such usage. ${ }^{3,4}$ Before clinical applications of these cells is possible, researchers and clinicians must overcome several problems including improved survival rate for the implanted cells, differentiation into the target cell type, and structural support that enables the reconstruction of the recipient tissues. ${ }^{5-8}$ To overcome the problems, the utilization of scaffolds, growth factors, ${ }^{11}$ and combinations of these materials ${ }^{12,13}$ has been investigated. The survival, differentiation, and reorganization of the implanted cells are affected by the microenvironment within the recipient tissues ${ }^{14-17}$; however, our understanding of these microenvironmental variables is currently insufficient to provide for clinically effective and reliable resources for regenerative medicine.

We previously showed that freeze-injury of the mouse urinary bladder resulted in localized destruction of the smooth muscle cells and layered organization. ${ }^{18}$ We also showed that mouse bone marrow-derived cells implanted into freeze-injured bladder walls differentiated into smooth muscle cells. These cells became organized into layered structures that were associated with the recovery of contractions in these urinary bladders. In contrast, bone marrow-derived cells implanted into intact bladder walls did not exhibit these behaviors. We hypothesized that the microenvironment within the injured urinary bladders was suitable to the development of functional smooth muscle layers and that these conditions were not present in the intact tissues. In this study, we have investigated the microenvironment of the injured urinary bladders by focusing on the microcirculation, layered smooth muscle structures, and growth factor mRNA expressions.

\section{Materials and Methods}

\section{Animals}

BALB/C nu/nu female nude mice (Japan SLC, Shizuoka, Japan) at postnatal week 5 were used for the experiments. Animals were treated in accordance with National Institutes of Health Animal Care Guidelines and the guidelines approved by the Animal Ethics Committee of Shinshu University School of Medicine.

\footnotetext{
${ }^{1}$ Department of Urology, Shinshu University School of Medicine, Matsumoto, Japan.

${ }^{2}$ Department of Urology, Nagoya University Graduate School of Medicine, Nagoya, Japan
} 


\section{Freeze-injury of urinary bladders}

Eighteen female nude mice were randomly separated into control intact urinary bladder $(n=9)$ and freeze-injured urinary bladder $(n=9)$ groups. The animals were anesthetized with a pentobarbital sodium solution $(0.05 \mathrm{mg} / \mathrm{g}$ body weight), and their urinary bladders were exposed through an abdominal midline incision. The posterior bladder walls were freeze-injured by application for $30 \mathrm{~s}$ of the $10 \times 3 \mathrm{~mm}$ end of an iron bar chilled by dry ice. The freezing caused a temporary cessation of blood flow to the area. After we confirmed that the frozen area was thawed and the blood flow recovered, the urinary bladders were returned to the pelvic cavity. The control urinary bladders were similarly exposed, and then were returned to the pelvic cavity without further manipulation. For the next 3 days, all of the animals were maintained under a 12$\mathrm{h}$ alternating light-dark cycle with freely available food and water. Three days after the operations, the urinary bladders were again exposed as described above to observe and calculate blood flow velocity by video microscopy (see below). After video microscopy, the urinary bladders were removed and separated into groups for histological and cytological analysis $(n=6)$ and real-time reverse transcription polymerase chain reaction (RT-PCR) arrays $(n=3)$.

\section{Calculation of blood flow velocity within intact and freeze-injured urinary bladders}

Calculation of blood flow velocity within capillaries in the control intact or wounded areas on the bladder walls was conducted as previously detailed. ${ }^{19}$ Three days after operation, the intact or wounded areas ( $n=9$ in each group) were viewed by pencil lens charge-coupled device (CCD) video microscopy and recorded on a digital videocassette recorder. Consecutive images of red blood cells flowing within six venous blood capillaries were collected at a rate 60 frame $/ \mathrm{s}$ for $20 \mathrm{~min}$. Using freeze-frame mode, a line segment was set along each capillary bed in consecutive images to construct a spatiotemporal image using the line-shift method. ${ }^{19}$ The blood flow velocity was calculated based upon the movement of red blood cells in the spatiotemporal images. ${ }^{19}$

\section{Immunohistochemistry}

The intact and freeze-injured urinary bladders $(n=3$ in each group) were removed and rinsed with $20 \mathrm{mM}$ phosphate buffered saline (PBS; $\mathrm{pH} 7.4$ ) at $4^{\circ} \mathrm{C}$. They were fixed in $4 \%$ paraformaldehyde and $4 \%$ sucrose in $0.1 \mathrm{M}$ phosphate buffer ( $\mathrm{pH}$ 7.4) for $12 \mathrm{~h}$ at $4^{\circ} \mathrm{C}$, and then embedded in paraffin. Each sample was cut into 5 - $\mu$ m-thick serial sections. The sections were deparaffinized, rehydrated, rinsed three times with PBS, and immersed in $10 \mathrm{mM}$ sodium citrate ( $\mathrm{pH} \mathrm{6.0).} \mathrm{For}$ antigen retrieval, they were then microwaved at $100^{\circ} \mathrm{C}$ for $5 \mathrm{~min}$. The specimens were coated with $1.5 \%$ normal donkey serum (Chemicon International, Temecula, CA) and 1.5\% nonfat milk in PBS for $1 \mathrm{~h}$ at $4^{\circ} \mathrm{C}$. They were then incubated for $12 \mathrm{~h}$ at $4{ }^{\circ} \mathrm{C}$ with $\alpha$ smooth muscle actin antibody (anti-SMA, ASM-1, 1:100, mouse monoclonal; Progen Biotechnik GmbH, Heidelberg, Germany) and uroplakin III antibody (M-17, 1:100, goat polyclonal; Santa Cruz Biotechnology, Santa Cruz, CA), a marker for urothelium. The sections were rinsed with PBS at $4^{\circ} \mathrm{C}$, and then incubated with secondary antibody consisting of donkey anti-mouse IgG conjugated with Alexa

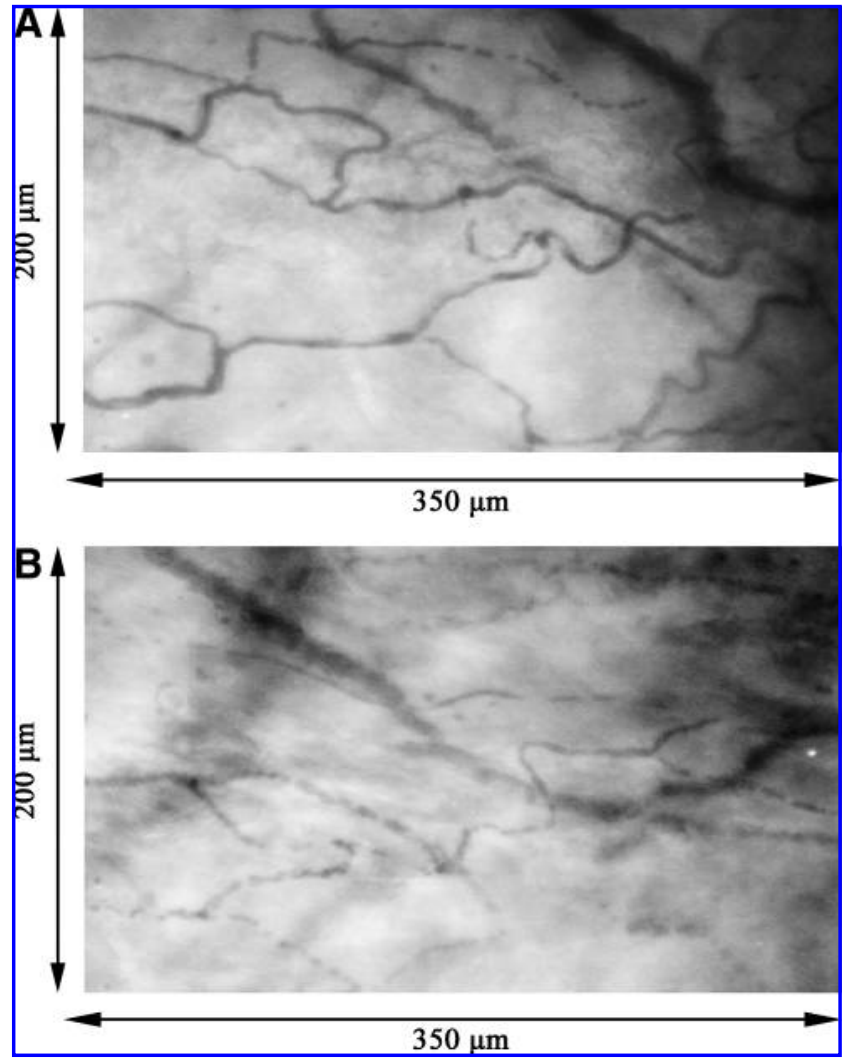

FIG. 1. Microcirculation viewed by pencil lens chargecoupled device (CCD) video microscopy 3 days after surgery. (A) The control areas in the intact bladder walls had blood capillaries with vigorously flowing red blood cells. (B) While the freeze-injured areas maintained partial microcirculation, blood capillaries were not as apparent compared to the controls.

fluor 488 and donkey anti-goat IgG conjugated with Alexa fluor 594 (1:250; Molecular Probes, Eugene, OR) for $1 \mathrm{~h}$ at $4^{\circ} \mathrm{C}$. Subsequently after rinsing, the sections were counterstained with $4^{\prime}$, 6-diamidino-2-phenylindole dihydrochloride $(5 \mu \mathrm{g} /$ $\mathrm{mL}$; Molecular Probes), and then coated with Fluorescent Mounting Medium (Dako Cytomation, Carpinteria, CA). The slides were observed and photographed with a Leica DAS Microscopethe (Leica Microsystems GmbH, Wetzlar, Germany). Other sections from each sample were stained with hematoxylin and eosin or by the ApopTag ${ }^{\circledR}$ ISOL fluorescence apoptosis detection technique (DNase Types I \& II; Chemicon International).

Table 1. Blood Flow Velocity Within Intact AND INJURED REgIONS

\begin{tabular}{lc}
\hline & $\begin{array}{c}\text { Blood flow } \\
\text { velocity }(\mathrm{mm} / \mathrm{s})\end{array}$ \\
\hline Intact-control regions & $0.26 \pm 0.03$ \\
Freeze-injured regions & $0.12 \pm 0.11^{\mathrm{a}}$ \\
\hline
\end{tabular}

The values were calculated from six blood capillaries in each animal.

${ }^{\mathrm{a}} p<0.05$, compared to the intact regions ( $n=9$ in each group). 

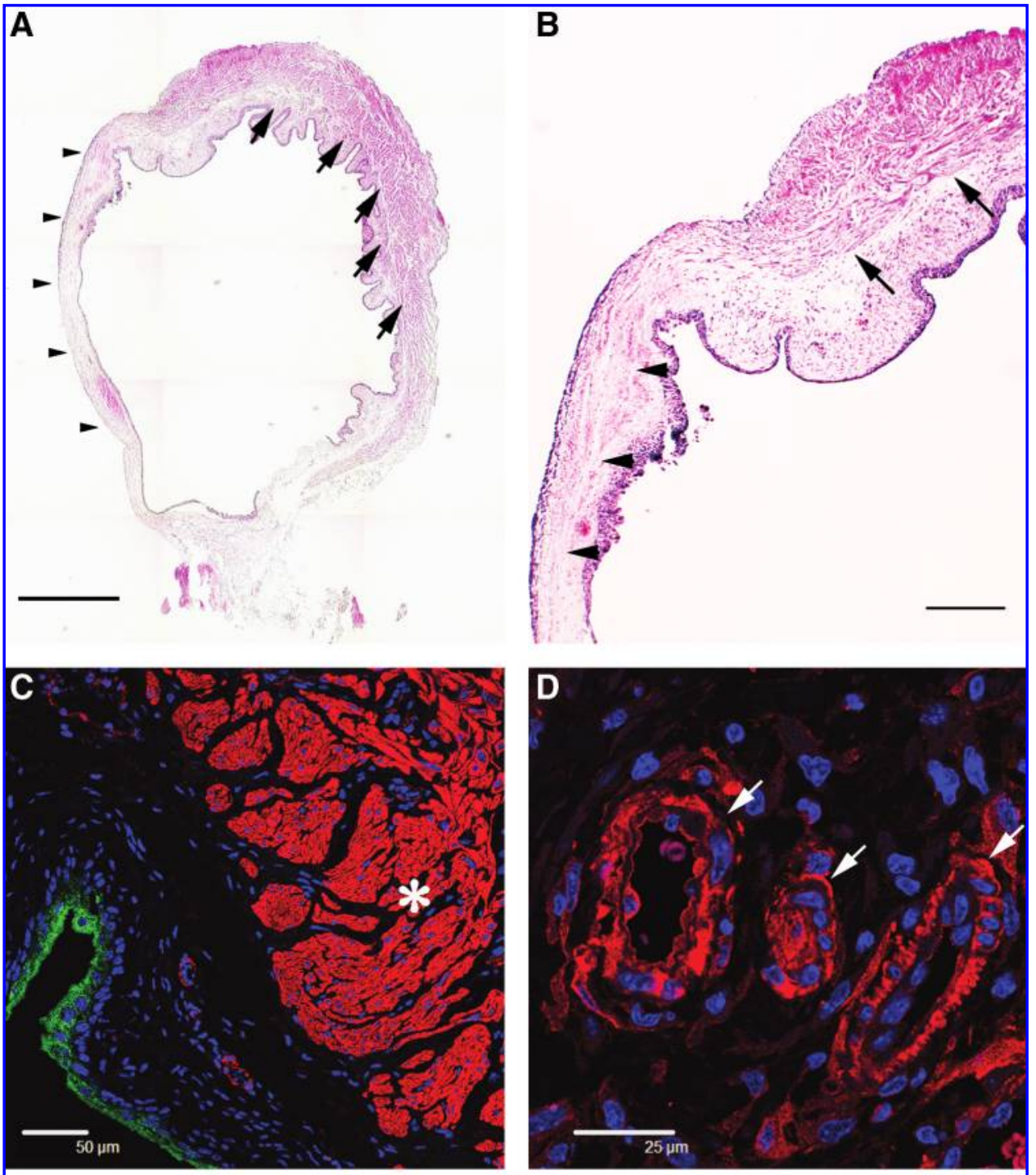

FIG. 2. Histochemistry of 3day smooth muscle layers and blood vessels within the intact and injured regions. (A) At 3 days after the freeze-injury operation, the injured urinary bladders had wounded (arrowheads) and undamaged (arrows) regions (hematoxylin and eosin). Bar $=2 \mathrm{~mm}$. (B)

The wounded region had diminished smooth muscle layers (arrowheads) that were adjacent to the undamaged region with abundant smooth muscle cells organized into layers (arrows) (hematoxylin and eosin). Bar $=100 \mu \mathrm{m}$. (C) The control regions in the intact bladder walls had clearly defined, thick, smooth muscle layers composed of SMApositive smooth muscle cells (red, asterisk). Bar $=50 \mu \mathrm{m}$.

(D) The blood vessels in the control regions contained many SMA-positive cells (red, arrows). Bar $=25 \mu \mathrm{m}$. (E) Within the freeze-injured regions, the remaining smooth muscle layers were thin and contained few SMA-positive cells (asterisk). Bar $=25 \mu \mathrm{m}$.
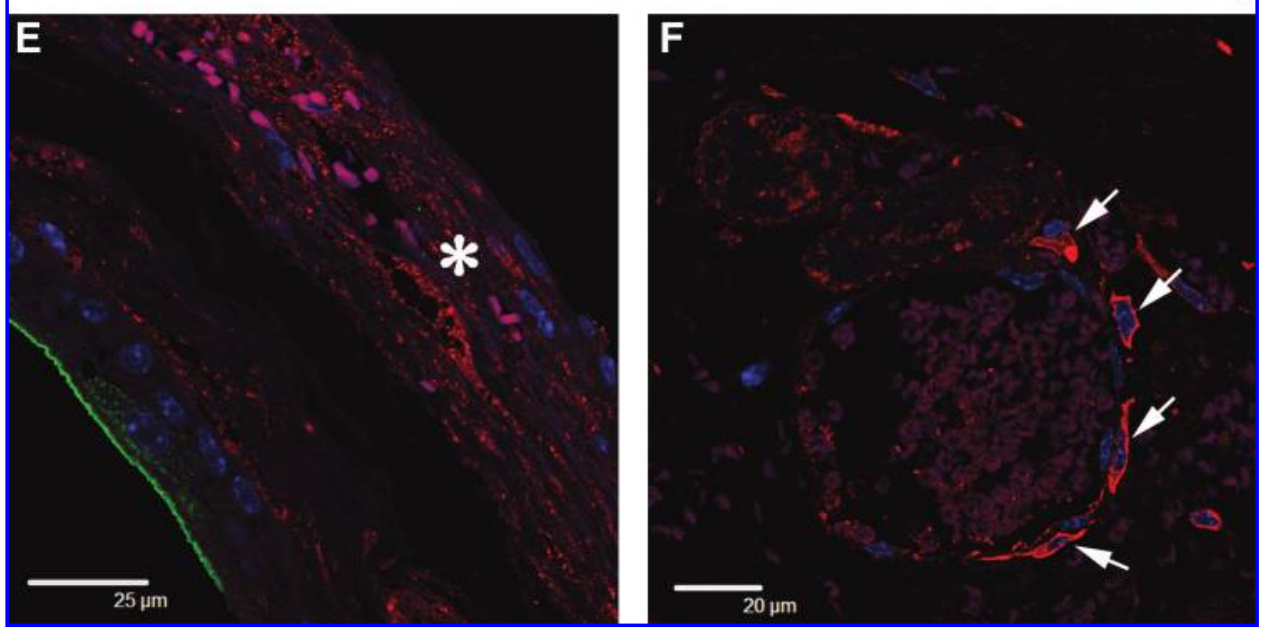
(F) The blood vessels in the injured regions contained only a few SMA-positive cells (red, arrows) and appeared to be fragile compared to control blood vessels. Bar $=20 \mu \mathrm{m}$. Green: uroplakin III; blue: nuclei.

\section{Electron microscopy}

The intact and injured urinary bladders $(n=3$ in each group) were fixed overnight in $2.5 \%$ glutaraldehyde in $45 \mathrm{mM}$ cacodylate buffer ( $\mathrm{pH}$ 7.2). The fixed specimens were trimmed, and separated for scanning electron microscopy (SEM) and transmission electron microscopy (TEM). For SEM, the glutaraldehyde-fixed specimens were washed with PBS, and postfixed for $60 \mathrm{~min}$ by $1 \%$ osmium tetroxide in $0.1 \mathrm{M}$ sodium cacodylate buffer, $\mathrm{pH} 7.2$ at $4^{\circ} \mathrm{C}$. After dehydrating in a 
graded series of ethanol, the specimens were rinsed in tertiary butyl alcohol. The specimens were freeze-dried, mounted on sample-holders, and coated by osmium. These samples were observed with a JEOL JSM-6000 SEM (JEOL, Tokyo, Japan) at an accelerating voltage of $15 \mathrm{kV}$. For TEM, the remaining glutaraldehyde-fixed specimens were washed three times in $180 \mathrm{mM}$ sucrose in $80 \mathrm{mM}$ cacodylate buffer at $4^{\circ} \mathrm{C}$ for $3 \mathrm{~h}$, and then postfixed in $1 \%$ osmium tetroxide in $0.1 \mathrm{M}$ sodium cacodylate buffer for $60 \mathrm{~min}$ at $4^{\circ} \mathrm{C}$. The specimens were dehydrated in a graded series of ethanol and embedded in epoxy resin. Ultrathin sections were stained with uranyl acetate and lead citrate. These samples were observed with a JEOL JEM1200 TEM (JEOL) at an accelerating voltage of $80 \mathrm{kV}$.

\section{Real-time RT-PCR array}

The mRNA expression levels of 84 growth factors in the intact and freeze-injured urinary bladders $(n=3$ in each group) were estimated by real-time RT-PCR arrays. Total RNA was extracted from intact and injured whole urinary bladders with the RNeasy Mini Kit (Qiagen, Valencia, CA). Single-strand complementary DNA (cDNA) was synthesized from $1.0 \mu \mathrm{g}$ of the total RNA with the RT ${ }^{2}$ First Strand Kit (SuperArray Bioscience, Frederick, MD). The synthesized cDNA was added into plates of the $\mathrm{RT}^{2}$ Profiler ${ }^{\mathrm{TM}}$ PCR Array (Mouse Growth Factor PCR Array, SuperArray) preloaded with 84 growth factor primers and the following five internal standard genes: $\beta$-glucuronidase (Gusb), hypoxanthine guanine phosphoribosyly transferase 1 (Hprt1), heat shock protein $90 \mathrm{kDa} \alpha$ (Hsp90ab1), glyceraldehyde-3-phosphate dehydrogenase (Gapdh), and $\beta$-actin $(A c t b)$. After an initial denaturation at $95^{\circ} \mathrm{C}$ for $10 \mathrm{~min}$, the samples underwent 40 cycles of denaturation at $95^{\circ} \mathrm{C}$ for $15 \mathrm{~s}$ followed by annealing and extension and $60^{\circ} \mathrm{C}$ for $1 \mathrm{~min}$ in a two-step cycler with a 7000 Sequence Detector (Applied Biosystems, Foster City, CA). The mRNA expression levels of the 84 growth factors were calculated as ratios to the preloaded internal standard genes. The expression change for each gene in freeze-injured bladders compared to control intact bladders was calculated.

\section{Statistical analysis}

Results were expressed as means \pm standard error of the means. We used Excel ${ }^{\circledR}$ statistical program (Esumi, Tokyo, Japan) to determine statistical differences by unpaired $t$-tests. Differences with $p<0.05$ were considered significant.

\section{Results}

\section{Blood flow velocity within freeze-injured regions}

Placement of the chilled iron bar caused the application site on the bladder walls to freeze. Within $10 \mathrm{~s}$ after removal of the bar, the frozen spot thawed due to body and/or room heat and appeared to the naked eye similar to the intact control bladder walls. However, when we monitored blood flow within the blood capillaries of the frozen area with CCD video microscopy, the blood flow paused for approximately $20 \mathrm{~min}$ after the operation, and then it resumed.

At 3 days after the freeze-injury operation, the wounded areas, which occupied approximately one-third of each urinary bladder, were readily identified. When observed by CCD video microscopy, blood capillaries in the control regions of the intact bladder walls had a robust flow of blood red cells (Fig. 1A) with a velocity of $0.26 \pm 0.03 \mathrm{~mm} / \mathrm{s}$ (Table 1). In contrast, while maintaining a partial microcirculation, blood capillaries within the injured regions of the wounded bladder walls were not as abundant compared to controls (Fig. 1B). Further, the blood flow velocity of the injured regions was $0.12 \pm 0.11 \mathrm{~mm} / \mathrm{s}(p<0.05$, Table 1$)$.

\section{Smooth muscle layers within freeze-injured regions}

At 3 days after the freeze-injury operation, the undamaged region within the injured urinary bladders had abundant smooth muscle cells organized into layers (Fig. 2A, B) similar to that of the uninjured control urinary bladders (Fig. 2C). However, the wounded site adjacent to the undamaged region had diminished smooth muscle layers (Fig. 2A, B). The control regions from the intact bladder walls had numerous SMA-positive smooth muscle cells that were organized into thick smooth muscle layers (Fig. 2C). In these regions, the walls of the blood vessels contained many SMA-positive smooth muscle cells (Fig. 2D). In contrast, the injured regions had few SMA-positive smooth muscle cells (Fig. 2E). The smooth muscle layers of the injured regions were more disorganized and thinner than those of the control regions. The blood vessels within the injured regions also had few SMA-positive cells, and they appeared to be more fragile than those of the controls (Fig. 2F).

By SEM, the control regions of the intact bladder walls had smooth muscle cells organized into layers that were readily apparent (Fig. 3A). These layers did not contain any porous spaces that were over $10 \mu \mathrm{m}$ in diameter (Fig. 3B). In contrast, the injured regions had few typical structures composed of smooth muscle cells (Fig. 3C). Additionally, there were many large porous spaces present that were over $10 \mu \mathrm{m}$ in diameter (Fig. 3D).

By TEM, the control regions of the intact bladder walls contained spindle-shaped smooth muscle cells with readily apparent nuclei (Fig. 4A). These cells were arranged in sheets and connected with each other by gap junctions. In contrast, smooth muscle cells in the injured regions were shrunken, and exhibited blebbing (Fig. 4B). The chromatin was condensed and nuclear fragmentation was apparent. Further, gap junctions were rarely present between the remaining cells of the smooth muscle layers. Apoptotic cells induced by caspase-dependent or caspase-independent pathway were not found within the control regions of the intact bladder walls (Fig. 5A). However, these cells were present within the injured regions (Fig. 5B). These findings indicated that the injured smooth muscle cells were declining in numbers due to apoptosis.

\section{Expression of growth factor mRNAs in freeze-injured urinary bladders}

Of the 84 growth factor mRNAs detectable by the PCR array, 19 growth factor mRNAs in the injured urinary bladders showed at least a twofold increase over the control urinary bladders (Table 2). For interleukins 6 (IL-6), 11 (IL-11), $1 \alpha$ $(I L-1 A), 1 \beta(I L-1 B)$, and $18(I L-18)$, the increases in mRNA expression ranged from 2.5- to 166-fold. For growth factors associated with angiogenesis, epiregulin (EREG), chemokine (C-X-C motif) ligand 1 (CXCL1), teratocarcinoma-derived growth factor (TDGF1), fibroblast growth factor 5 (FGF5), C-fos-induced growth factor (FIGF), and vascular endothe- 

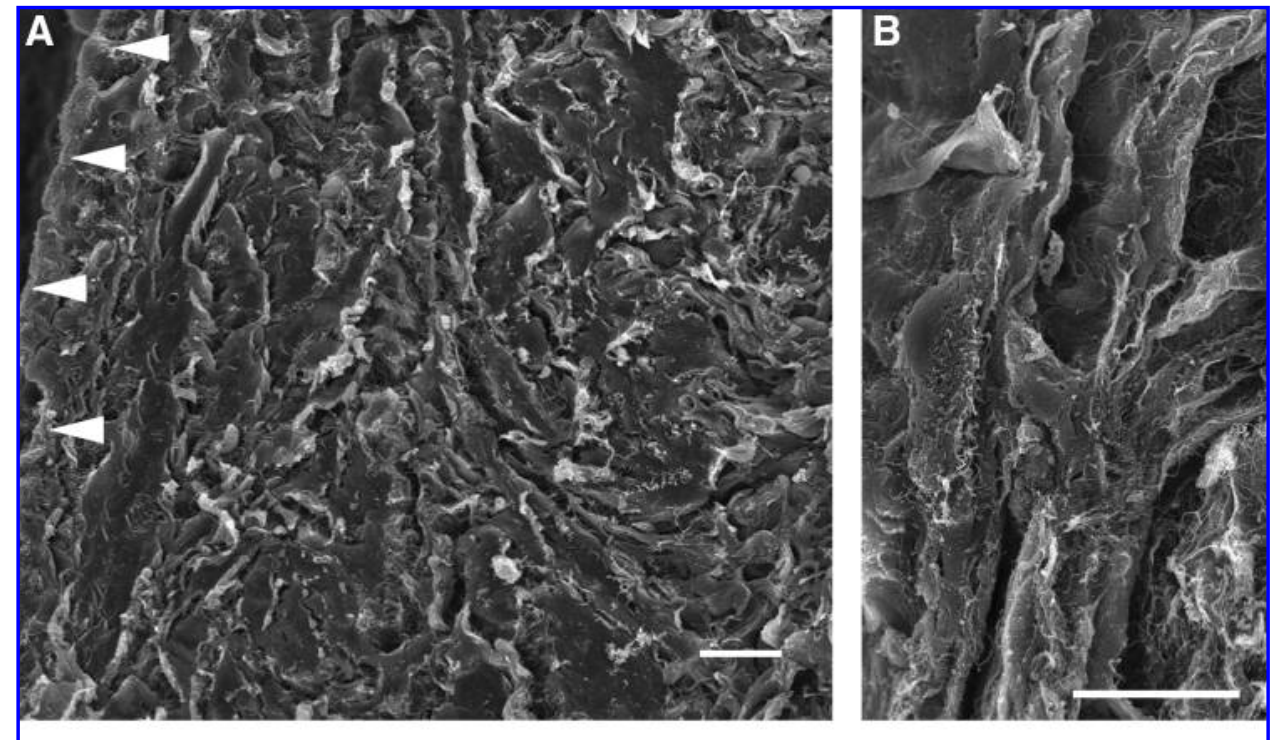

FIG. 3. Scanning electron microscopy of 3-day layered smooth muscle structures within the intact and injured regions. (A) The control regions of the intact bladder walls contained layered structures composed of smooth muscle cells. Arrowheads indicate exterior surface of the bladder wall. (B) The intact smooth muscle layers
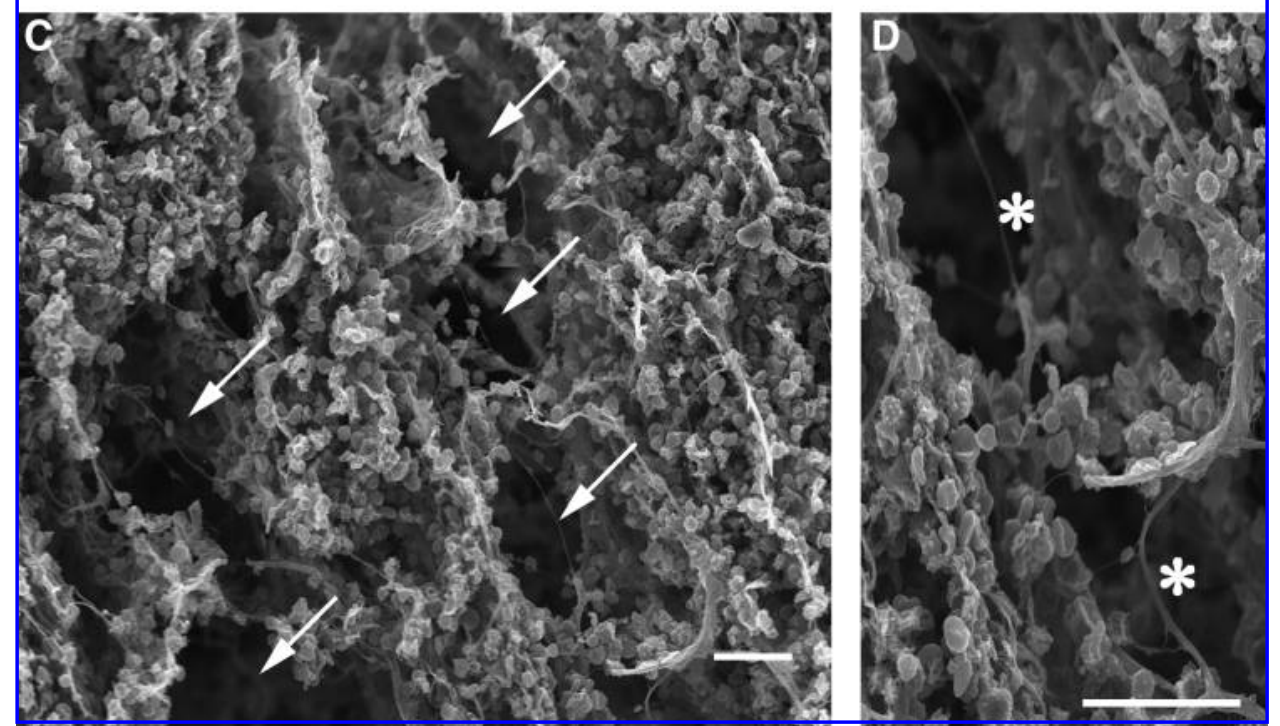
did not contain any large porous spaces. (C) The freezeinjured regions had few typical layered structures composed of smooth muscle cells. However, they did have many large porous spaces (arrows). (D) The porous spaces (asterisks) were over $10 \mu \mathrm{m}$ in diameter. Bar $=10 \mu \mathrm{m}$.

lial growth factor A (VEGFA), the increases in mRNA expression ranged from 2.3- to 16-fold. For mRNAs associated with wound healing, trefoil factor 1 (TFF1), colony stimulating factor 3 (CSF3), hepatocyte growth factor (HGF), and bone morphogenetic protein 1 (BMP1), the increases ranged from 2 - to 12.6-fold. For growth factors that play roles in the differentiation of smooth muscle cells, secreted phosphoprotein 1 (SPP1), inhibin $\beta-A$ (INHBA), glial cell line-derived neurotrophic factor $(G D N F)$, and transforming growth factor $\beta 1$ (TGFB1), the increases above controls ranged from 2.9- to 998fold.

\section{Discussion}

The microenvironment within the damaged recipient tissues affects regeneration of functional tissues. ${ }^{14-17}$ In our previous study, we freeze-injured urinary bladders with the same methods used in the present study, and 3 days later we implanted bone marrow-derived cells into the injured bladder walls. ${ }^{18}$ Fourteen days after implantation, the injured regions had distinct smooth muscle layers composed of smooth muscle cells that had differentiated from the bone marrowderived cells. ${ }^{18}$ In contrast, injured regions injected with cellfree control solution did not form layered structures. Thus, the bone marrow-derived cells survived and differentiated into smooth muscle cells in the freeze-injured bladder walls. However, the bone marrow-derived cells implanted into intact bladder walls did not survive. ${ }^{18}$ We hypothesized that at 3 days after freeze-injury, the bladders had an appropriate microenvironment that was crucial for the survival and differentiation of the implanted bone marrow-derived cells, which then regenerated the smooth muscle layers. In the current tissue engineering study, we investigated changes in the microenvironment that were associated with the development of layered smooth muscle structures and expression of growth factor mRNAs.

Immediately after freeze-injury, the thawed urinary bladders appeared, to the naked eye, similar to the intact ones. However, blood flow within the blood capillaries in the wound areas paused for approximately $20 \mathrm{~min}$ and then recovered. Therefore, we suggest that our freeze-injured urinary bladders might experience a period of ischemia followed by 
reperfusion as described by one of the microcirculation dysfunction models. ${ }^{19}$ At 3 days after, within the control intact regions in the uninjured urinary bladders, the blood vessel walls contained many smooth muscle cells and blood flowed abundantly in the capillaries. In contrast, blood vessels in the freeze-injured regions appeared fragile and contained few smooth muscle cells. The capillaries were sparse compared to the control regions, and the blood flow was significantly reduced. The mechanism(s) for the reduced flow rate is not known with certainty. Regardless of the reason, the most important finding is that the injured regions were maintained with only a partial microcirculation. The maintenance of at least a minimal microcirculation to provide oxygen and nutrition is likely to be one of the prerequisite factors necessary for successful tissue engineering.

In the injured regions, the number of smooth muscle cells in the wall of the urinary bladder was greatly reduced, and the SMA-positive cells that were present were not organized into smooth muscle layers. Based on the histological and cytological observations, smooth muscle cell death was predominantly caused by apoptosis, though we cannot exclude the occurrence of necrosis, especially immediately after the freeze-injury. The bladder walls contained numerous large pores that were not present in the control regions of the intact bladder walls. The origin of these pores is not certain, but could be caused by loss of smooth muscle cells that are the principal component of the wall in intact urinary bladders. It is possible that these pores might be helpful for a high rate of implanted cell survival and/or serve as scaffolding for the reconstruction of tissue structures.

The injured urinary bladders significantly upregulated growth factor mRNAs of SPP1, INHBA, GDNF, and TGFB1 compared to the intact urinary bladders. TGFB1 specifically promotes differentiation of smooth muscle cells from bone marrow-derived cells. ${ }^{20-23}$ The others, SPP $1,{ }^{24,25}$ INHBA, ${ }^{26-31}$ and GDNF, ${ }^{32-34}$ also support differentiation of smooth muscle cells from bone marrow-derived cells. In addition, the inflammation-related cytokine growth factor mRNAs $I L-6$, $I L-11, I L-1 A, I L-1 B$, and $I L-18$ were upregulated along with angiogenic-associated growth factor mRNAs EREG, CXCL1, ${ }^{35,36}$ TDGF1, ${ }^{37}$ FGF5, ${ }^{38}$ and VEGFA that have the potential to improve microcirculation within the injured regions. While the roles of TFF $1,{ }^{39,40} \mathrm{CSF} 3,{ }^{41} \mathrm{HGF}$, and BMP1 are unclear, these growth factors might participate in wound healing. Collectively, these results show that cells of the urinary bladder respond to freeze-injury by enhanced transcription of mRNAs. If translated, expression of these genes could promote growth and development of a suitable physical and biochemical environment. In turn, this environment could promote organization of the developing cells into physiologically functional tissues.

Our results are consistent with our previous study showing that functional smooth muscle layers developed after implantation of bone marrow-derived cells into freeze-injured bladder walls. ${ }^{18}$ Tissue engineering is composed of three factors: (i) undifferentiated cells having the potential to differentiate into specific cell types, (ii) scaffolding to support construction of tissue structures, and (iii) growth factors to promote differentiation of various and specific cell types. The bone marrow-derived cells served as the source of undifferentiated cells that develop into smooth muscle cells. ${ }^{20,42-45}$ In this study, the tissue pores that were present 3 days after
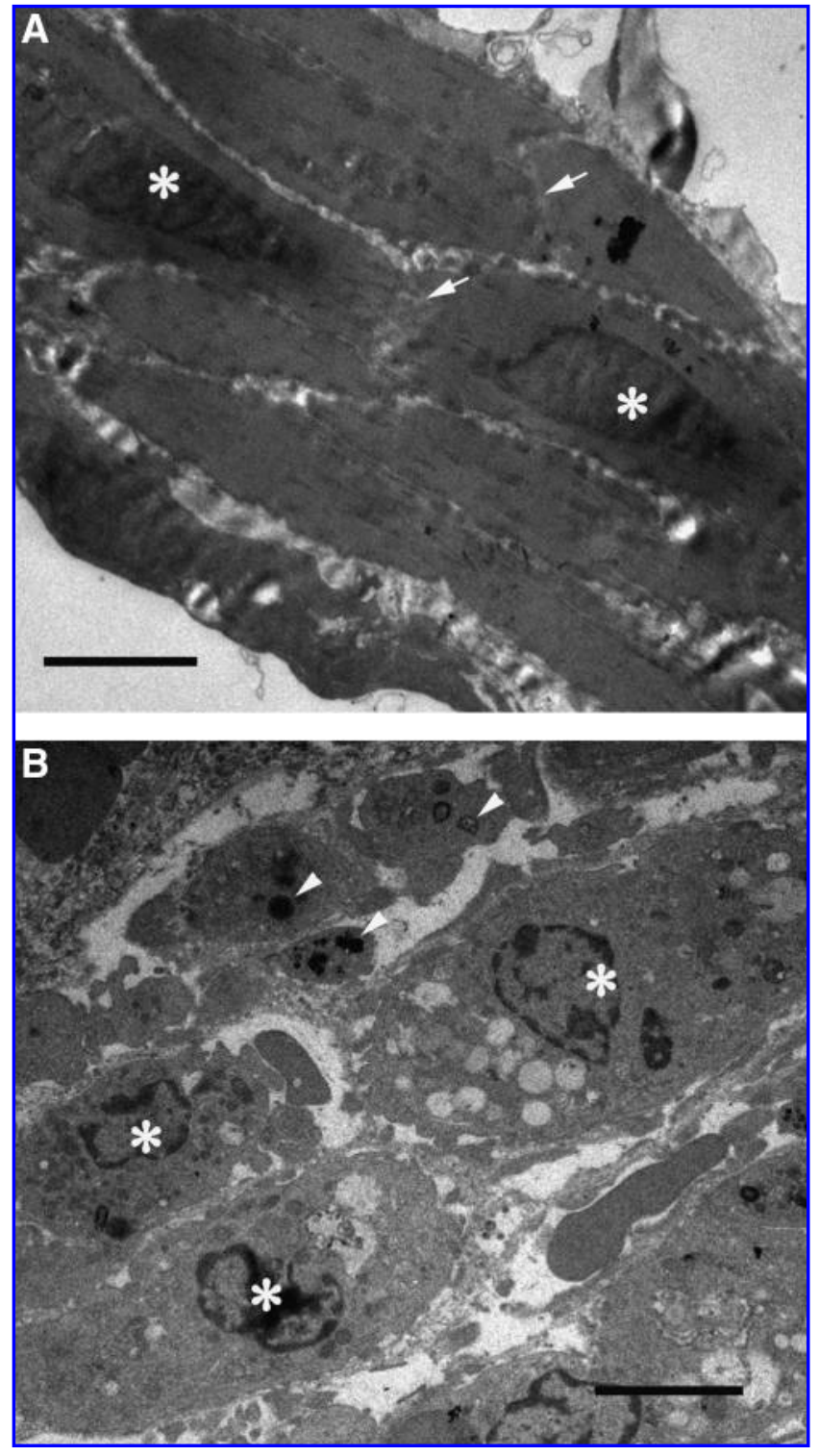

FIG. 4. Transmission electron microscopy of 3-day smooth muscle cells within the intact and injured regions. (A) In the intact control bladder walls, smooth muscle cells, containing large, well-formed nuclei (asterisks), were spindle-shaped and arranged in sheets. Adjacent smooth muscle cells were connected by gap junctions (arrows). (B) Smooth muscle cells (asterisks) within the freeze-injured regions showed shrinkage and blebbing. Nuclei of the injured cells (arrowheads) showed chromatin condensation and nuclear fragmentation. Gap junctions were rarely present between the remaining cells of the smooth muscle layers. Bar $=10 \mu \mathrm{m}$.

injury might have provided scaffolding and spaces suitable for colonization by the implanted bone marrow-derived cells. This would have optimized the chance for a high rate of cell survival and differentiation. Although we have not actually measured the secretion of growth factors by the surviving cells, at least 19 different growth factor mRNAs were increased 3 days after injury. Included in these were growth factor mRNAs for SPP1, INHBA, GDNF, and TGFB1. If they were translated, they could have supported the differentiation 


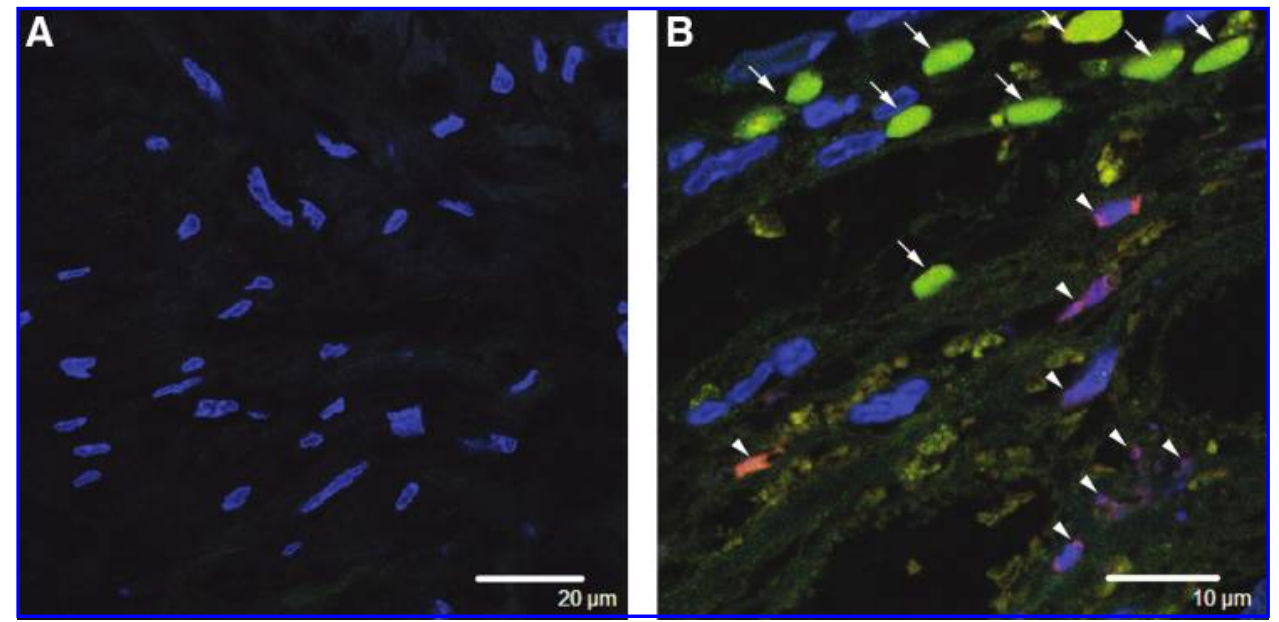

FIG. 5. Histochemistry of apoptotic cells within the intact and injured regions. (A) In control walls from uninjured urinary bladders, no apoptotic cells were identified. Bar $=20 \mu \mathrm{m}$. (B) The injured regions had numerous apoptotic cells induced by caspase-dependent (arrowheads, red) and caspaseindependent (arrows, green) pathways. Bar $=10 \mu \mathrm{m}$. Blue: nuclei.

of implanted bone marrow-derived cells into smooth muscle cells. Finally, the maintenance of a minimal microcirculation within the injured regions probably supported the implanted bone marrow-derived cells. For all of these reasons, the freeze-injured urinary bladder walls would have been suitable for differentiation and development of the implanted bone marrow-derived cells.

It is likely that recovery within the freeze-injured urinary bladders requires participation of the undamaged tissue adjacent to the injured site. In general, the success of implanted undifferentiated cells is likely to depend upon the recovery of host cells at the location of the injury or disease site. In urology, there is a need for regenerative medicine for irreversible or chronic diseases and/or injuries of the urinary bladder due to spinal injury or radiation therapy. For these cases, there may not be any recovery processes in the host tissues. To overcome the problems, it may be a possible to utilize bone marrow-derived cells. These cells not only develop into target tissues but also produce various growth factors associated with recovery in recipient tissues. ${ }^{46,47}$ However, the produc- tion of growth factors by the bone marrow-derived cells also depends on the surrounding microenvironment. ${ }^{48,49}$ Therefore, tissue engineering and regenerative medicine will fail unless the diseased or injured systems have the proper microenvironment or unless it can be provided.

Based on investigations, applications, and techniques of tissue engineering, the proper systems might be produced by utilization of scaffolds and/or growth factors. For the recipient tissues that do not have spaces for the implanted cells to survive, in vitro scaffolds made with biomaterials could be used to colonize the implanted cells. For the appropriate cellular differentiation, growth factors delivered by sustainedrelease or other drug delivery systems would be needed.

In conclusion, further understanding of the requirements for undifferentiated cell proliferation and targeted differentiation will be important in tissue engineering. Equally important for the successful application of tissue engineering methods to be clinically useful regenerative medicine, further knowledge of each unique microenvironment within recipient tissues is necessary.

Table 2. Upregulated Growth Factor mRNAs In Freeze-Injured Urinary Bladders

\begin{tabular}{|c|c|c|c|}
\hline Gene name & GenBank no. & Fold change & $\mathrm{p}-$ Value $e^{\mathrm{a}}$ \\
\hline Secreted phosphoprotein 1 (SPP1) & NM_009263 & 998.30 & 0.00002 \\
\hline Interleukin 6 (IL6) & NM_031168 & 166.19 & 0.00008 \\
\hline Interleukin 11 (IL11) & NM_008350 & 43.01 & 0.00032 \\
\hline Inhibin $\beta$-A (INHBA) & NM_008380 & 31.34 & 0.00001 \\
\hline Interleukin 1 aplha (IL1A) & NM_010554 & 28.51 & 0.00024 \\
\hline Interleukin $1 \beta(I L 1 B)$ & NM_008361 & 24.48 & 0.00051 \\
\hline Epiregulin $(E R E G)$ & NM_007950 & 15.93 & 0.00017 \\
\hline Trefoil factor 1 (TFF1) & NM_009362 & 12.55 & 0.00057 \\
\hline Glial cell derived neurotrophic factor (GDNF) & NM_010275 & 7.40 & 0.04639 \\
\hline Chemokin (C-X-C motif) ligand 1 (CXCL1) & NM_008176 & 5.98 & 0.00110 \\
\hline Colony stimulating factor 3 (CSF3) & NM_009971 & 4.38 & 0.00118 \\
\hline Teratocarcinoma-derived growth factor (TDGF1) & NM_011562 & 3.33 & 0.01727 \\
\hline Fibroblast growth factor 5 (FGF5) & NM_010203 & 2.94 & 0.01079 \\
\hline Transforming growth factor, $\beta 1$ (TGFB1) & NM_011577 & 2.85 & 0.00005 \\
\hline C-fos induced growth factor (FIGF) & NM_010216 & 2.57 & 0.00484 \\
\hline Interleukin 18 (IL18) & NM_008360 & 2.46 & 0.01285 \\
\hline Vascular endothelial growth factor $\mathrm{A}$ (VEGFA) & NM_009505 & 2.33 & 0.00295 \\
\hline Hepatocyte growth factor (HGF) & NM_010427 & 2.08 & 0.00801 \\
\hline Bone morphogenetic protein 1 (BMP1) & NM_009755 & 2.00 & 0.00984 \\
\hline
\end{tabular}

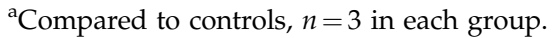




\section{Disclosure Statement}

No competing financial interests exist.

\section{References}

1. Waksman, R., and Baffour, R. Bone marrow and bone marrow derived mononuclear stem cells therapy for the chronically ischemic myocardium. Cardiovasc Radiat Med 4, 164, 2003.

2. Wang, X.J., and Li, Q.P. The roles of mesenchymal stem cells (MSCs) therapy in ischemic heart diseases. Biochem Biophys Res Commun 359, 189, 2007.

3. Jiang, Y., Vaessen, B., Lenvik, T., Blackstad, M., Reyes, M., and Verfaillie, C.M. Multipotent progenitor cells can be isolated from postnatal murine bone marrow, muscle, and brain. Exp Hematol 30, 896, 2002.

4. Peister, A., Mellad, J.A., Larson, B.L., Hall, B.M., Gibson, L.F., and Prockop, D.J. Adult stem cells from bone marrow (MSCs) isolated from different strains of inbred mice vary in surface epitopes, rates of proliferation, and differentiation potential. Blood 103, 1662, 2004.

5. Abdallah, B.M., and Kassem, M. Human mesenchymal stem cells: from basic biology to clinical applications. Gene Ther 15, 109, 2008.

6. Devine, S.M. Mesenchymal stem cells: will they have a role in the clinic? J Cell Biochem Suppl 38, 73, 2002.

7. Haider, H., and Ashraf, M. Bone marrow cell transplantation in clinical perspective. J Mol Cell Cardiol 38, 225, 2005.

8. Kassem, M., and Abdallah, B.M. Human bone-marrowderived mesenchymal stem cells: biological characteristics and potential role in therapy of degenerative diseases. Cell Tissue Res 331, 157, 2008.

9. Dahl, S.L., Koh, J., Prabhakar, V., and Niklason, L.E. Decellularized native and engineered arterial scaffolds for transplantation. Cell Transplant 12, 659, 2003.

10. Guan, J., Stankus, J.J., and Wagner, W.R. Development of composite porous scaffolds based on collagen and biodegradable poly(ester urethane)urea. Cell Transplant 15 Suppl 1, S17, 2006.

11. Owens, G.K. Regulation of differentiation of vascular smooth muscle cells. Physiol Rev 75, 487, 1995.

12. Bian, J., Kiedrowski, M., Mal, N., Forudi, F., and Penn, M.S. Engineered cell therapy for sustained local myocardial delivery of nonsecreted proteins. Cell Transplant 15, 67, 2006.

13. Patel, A.N., Spadaccio, C., Kuzman, M., Park, E., Fischer, D.W., Stice, S.L., Mullangi, C., and Toma, C. Improved cell survival in infarcted myocardium using a novel combination transmyocardial laser and cell delivery system. Cell Transplant 16, 899, 2007.

14. Coyne, T.M., Marcus, A.J., Woodbury, D., and Black, I.B. Marrow stromal cells transplanted to the adult brain are rejected by an inflammatory response and transfer donor labels to host neurons and glia. Stem Cells 24, 2483, 2006.

15. Dai, W., Field, L.J., Rubart, M., Reuter, S., Hale, S.L., Zweigerdt, R., Graichen, R.E., Kay, G.L., Jyrala, A.J., Colman, A., Davidson, B.P., Pera, M., and Kloner, R.A. Survival and maturation of human embryonic stem cell-derived cardiomyocytes in rat hearts. J Mol Cell Cardiol 43, 504, 2007.

16. Djouad, F., Delorme, B., Maurice, M., Bony, C., Apparailly, F., Louis-Plence, P., Canovas, F., Charbord, P., Noel, D., and Jorgensen, C. Microenvironmental changes during differentiation of mesenchymal stem cells towards chondrocytes. Arthritis Res Ther 9, R33, 2007.
17. Srivastava, A.S., Shenouda, S., Mishra, R., and Carrier, E. Transplanted embryonic stem cells successfully survive, proliferate, and migrate to damaged regions of the mouse brain. Stem Cells 24, 1689, 2006.

18. Imamura, T., Kinebuchi, Y., Ishizuka, O., Seki, S., Igawa, Y., and Nishizawa, O. Implanted mouse bone marrow-derived cells reconstruct layered smooth muscle structures in injured urinary bladders. Cell Transplant 17, 267, 2008.

19. Yamamoto, T., Tada, T., Brodsky, S.V., Tanaka, H., Noiri, E., Kajiya, F., and Goligorsky, M.S. Intravital videomicroscopy of peritubular capillaries in renal ischemia. Am J Physiol Renal Physiol 282, F1150, 2002.

20. Kanematsu, A., Yamamoto, S., Iwai-Kanai, E., Kanatani, I., Imamura, M., Adam, R.M., Tabata, Y., and Ogawa, O. Induction of smooth muscle cell-like phenotype in marrowderived cells among regenerating urinary bladder smooth muscle cells. Am J Pathol 166, 565, 2005.

21. Kinner, B., Zaleskas, J.M., and Spector, M. Regulation of smooth muscle actin expression and contraction in adult human mesenchymal stem cells. Exp Cell Res 278, 72, 2002.

22. Narita, Y., Yamawaki, A., Kagami, H., Ueda, M., and Ueda, Y. Effects of transforming growth factor-beta 1 and ascorbic acid on differentiation of human bone-marrow-derived mesenchymal stem cells into smooth muscle cell lineage. Cell Tissue Res 333, 449, 2008.

23. Wang, D., Park, J.S., Chu, J.S., Krakowski, A., Luo, K., Chen, D.J., and Li, S. Proteomic profiling of bone marrow mesenchymal stem cells upon transforming growth factor beta1 stimulation. J Biol Chem 279, 43725, 2004.

24. Lenga, Y., Koh, A., Perera, A.S., McCulloch, C.A., Sodek, J., and Zohar, R. Osteopontin expression is required for myofibroblast differentiation. Circ Res 102, 319, 2008.

25. Pereira, R.O., Carvalho, S.N., Stumbo, A.C., Rodrigues, C.A., Porto, L.C., Moura, A.S., and Carvalho, L. Osteopontin expression in coculture of differentiating rat fetal skeletal fibroblasts and myoblasts. In Vitro Cell Dev Biol Anim 42, 4, 2006.

26. Agrotis, A., Samuel, M., Prapas, G., and Bobik, A. Vascular smooth muscle cells express multiple type I receptors for TGF-beta, activin, and bone morphogenetic proteins. Biochem Biophys Res Commun 219, 613, 1996.

27. Cho, S.H., Yao, Z., Wang, S.W., Alban, R.F., Barbers, R.G., French, S.W., and Oh, C.K. Regulation of activin A expression in mast cells and asthma: its effect on the proliferation of human airway smooth muscle cells. J Immunol 170, 4045, 2003.

28. Ishisaki, A., Hayashi, H., Li, A.J., and Imamura, T. Human umbilical vein endothelium-derived cells retain potential to differentiate into smooth muscle-like cells. J Biol Chem 278, 1303, 2003.

29. Kojima, I., Mogami, H., Kawamura, N., Yasuda, H., and Shibata, H. Modulation of growth of vascular smooth muscle cells by activin A. Exp Cell Res 206, 152, 1993.

30. Riedy, M.C., Brown, M.C., Molloy, C.J., and Turner, C.E. Activin A and TGF-beta stimulate phosphorylation of focal adhesion proteins and cytoskeletal reorganization in rat aortic smooth muscle cells. Exp Cell Res 251, 194, 1999.

31. You, L., and Kruse, F.E. Differential effect of activin A and BMP-7 on myofibroblast differentiation and the role of the Smad signaling pathway. Invest Ophthalmol Vis Sci 43, 72, 2002.

32. Sparrow, M.P., and Lamb, J.P. Ontogeny of airway smooth muscle: structure, innervation, myogenesis and function in the fetal lung. Respir Physiol Neurobiol 137, 361, 2003. 
33. Suarez-Rodriguez, R., and Belkind-Gerson, J. Cultured nestinpositive cells from postnatal mouse small bowel differentiate ex vivo into neurons, glia, and smooth muscle. Stem Cells 22, 1373, 2004

34. Tollet, J., Everett, A.W., and Sparrow, M.P. Development of neural tissue and airway smooth muscle in fetal mouse lung explants: a role for glial-derived neurotrophic factor in lung innervation. Am J Respir Cell Mol Biol 26, 420, 2002.

35. Li, M., Carpio, D.F., Zheng, Y., Bruzzo, P., Singh, V., Ouaaz, F., Medzhitov, R.M., and Beg, A.A. An essential role of the NF-kappa B/Toll-like receptor pathway in induction of inflammatory and tissue-repair gene expression by necrotic cells. J Immunol 166, 7128, 2001.

36. Yamada, H., Takahashi, S., Fujita, H., Kobayashi, N., and Okabe, S. Cytokine-induced neutrophil chemoattractants in healing of gastric ulcers in rats: expression of $>40-\mathrm{kDa}$ chemoattractant in delayed ulcer healing by indomethacin Dig Dis Sci 44, 889, 1999.

37. Gerecht-Nir, S., Dazard, J.E., Golan-Mashiach, M., Osenberg, S., Botvinnik, A., Amariglio, N., Domany, E., Rechavi, G., Givol, D., and Itskovitz-Eldor, J. Vascular gene expression and phenotypic correlation during differentiation of human embryonic stem cells. Dev Dyn 232, 487, 2005.

38. Brogi, E., Winkles, J.A., Underwood, R., Clinton, S.K., Alberts, G.F., and Libby, P. Distinct patterns of expression of fibroblast growth factors and their receptors in human atheroma and nonatherosclerotic arteries. Association of acidic FGF with plaque microvessels and macrophages. J Clin Invest 92, 2408, 1993.

39. Oertel, M., Graness, A., Thim, L., Buhling, F., Kalbacher, H., and Hoffmann, W. Trefoil factor family-peptides promote migration of human bronchial epithelial cells: synergistic effect with epidermal growth factor. Am J Respir Cell Mol Biol 25, 418, 2001.

40. Playford, R.J. Trefoil peptides: what are they and what do they do? J R Coll Physicians Lond 31, 37, 1997.

41. He, J.Q., Shumansky, K., Connett, J.E., Anthonisen, N.R., Pare, P.D., and Sandford, A.J. Association of genetic variations in the CSF2 and CSF3 genes with lung function in smoking-induced COPD. Eur Respir J 32, 25, 2008.

42. Hegner, B., Weber, M., Dragun, D., and Schulze-Lohoff, E. Differential regulation of smooth muscle markers in human bone marrow-derived mesenchymal stem cells. J Hypertens 23, 1191, 2005
43. Jerareungrattan, A., Sila-asna, M., and Bunyaratvej, A. Increased smooth muscle actin expression from bone marrow stromal cells under retinoic acid treatment: an attempt for autologous blood vessel tissue engineering. Asian Pac J Allergy Immunol 23, 107, 2005.

44. Shukla, D., Box, G.N., Edwards, R.A., and Tyson, D.R. Bone marrow stem cells for urologic tissue engineering. World J Urol 26, 341, 2008.

45. Tamama, K., Sen, C.K., and Wells, A. Differentiation of bone marrow mesenchymal stem cells into the smooth muscle lineage by blocking ERK/MAPK signaling pathway. Stem Cells Dev 17, 897, 2008.

46. Crisostomo, P.R., Wang, Y., Markel, T.A., Wang, M., Lahm, T., and Meldrum, D.R. Human mesenchymal stem cells stimulated by TNF-alpha, LPS, or hypoxia produce growth factors by an NF kappa B- but not JNK-dependent mechanism. Am J Physiol Cell Physiol 294, C675, 2008.

47. Nishida, T., Tsuji, S., Tsujii, M., Ishii, S., Yoshio, T., Shinzaki, S., Egawa, S., Irie, T., Kakiuchi, Y., Yasumaru, M., Iijima, H., Tsutsui, S., Kawano, S., and Hayashi, N. Cultured bone marrow cell local implantation accelerates healing of ulcers in mice. J Gastroenterol 43, 124, 2008.

48. Bratincsak, A., Lonyai, A., Shahar, T., Hansen, A., Toth, Z.E., and Mezey, E. Using brain slice cultures of mouse brain to assess the effect of growth factors on differentiation of bone marrow derived stem cells. Ideggyogy Sz 60, 124, 2007.

49. Ohnishi, S., Yasuda, T., Kitamura, S., and Nagaya, N. Effect of hypoxia on gene expression of bone marrow-derived mesenchymal stem cells and mononuclear cells. Stem Cells 25, 1166, 2007.

Address correspondence to: Tetsuya Imamura, Ph.D.

Department of Urology

Shinshu University School of Medicine 3-1-1 Asahi

Matsumoto 390-8621

Japan

E-mail: imatetu@shinshu-u.ac.jp

Received: January 18, 2009

Accepted: April 27, 2009

Online Publication Date: June 17, 2009 
